\title{
Lifestyle modification in the management of the metabolic syndrome: achievements and challenges
}

This article was published in the following Dove Press journal:

Diabetes, Metabolic Syndrome and Obesity:Targets and Therapy

29 October 2010

Number of times this article has been viewed

\author{
Riccardo Dalle Grave' \\ Simona Calugi' \\ Elena Centis ${ }^{2}$ \\ Rebecca Marzocchi ${ }^{2}$ \\ Marwan El Ghoch' \\ Giulio Marchesini \\ 'Department of Eating \& Weight \\ Disorder, Villa Garda Hospital, \\ Garda (VR), Italy; ${ }^{2}$ Unit of Metabolic \\ Diseases \& Clinical Dietetics, Alma \\ Mater Studiorum - University of \\ Bologna, Bologna, Italy
}

\begin{abstract}
Lifestyle modification based on behavior therapy is the most important and effective strategy to manage the metabolic syndrome. Modern lifestyle modification therapy combines specific recommendations on diet and exercise with behavioral and cognitive strategies. The intervention may be delivered face-to-face or in groups, or in groups combined with individual sessions. The main challenge of treatment is helping patients maintain healthy behavior changes in the long term. In the last few years, several strategies have been evaluated to improve the long-term effect of lifestyle modification. Promising results have been achieved by combining lifestyle modification with pharmacotherapy, using meals replacement, setting higher physical activity goals, and long-term care. The key role of cognitive processes in the success/failure of weight loss and maintenance suggests that new cognitive procedures and strategies should be included in the traditional lifestyle modification interventions, in order to help patients build a mind-set favoring long-term lifestyle changes. These new strategies raise optimistic expectations for an effective treatment of metabolic syndrome with lifestyle modifications, provided public health programs to change the environment where patients live support them.
\end{abstract}

Keywords: metabolic syndrome, obesity, lifestyle modification, cognitive behavior therapy

\section{Introduction}

The metabolic syndrome (MS) is a clinical condition characterized by a cluster of abnormalities, including visceral obesity, hyperinsulinemia and insulin resistance, ${ }^{1}$ type 2 diabetes, dyslipidemia, hypertension, fatty liver, and elevated uric acid, a procoagulant state, whose borders are only provisionally set by different international agencies (Table 1). ${ }^{2-5}$ The focus is given to visceral obesity, ${ }^{6}$ which is considered the pivotal alteration according to the International Diabetes Federation, ${ }^{4}$ and to atherogenic dyslipidemia, which covers two of the five diagnostic criteria. The prevalence of MS is increasing worldwide in parallel with the alarming rise of obesity; ${ }^{7}$ according to the National Health and Nutrition Examination Survey, MS is estimated to affect up to $36 \%$ of the US adult population, ${ }^{8}$ with a lower prevalence in Europe. ${ }^{9}$ Although the accepted cutoffs of individual variables do not constitute per se evidence of risk factors, the clustering of abnormalities carries a high risk of the diabetes and cardiovascular diseases. In particular, the presence of MS is associated with a two- to four-fold increase of cardiovascular disease-related morbidity and mortality, ${ }^{10,11}$ even in the absence of clinically evident cardiovascular disease or diabetes mellitus. ${ }^{12,13}$

MS affects people whose excess weight and sedentary life determine the phenotypical expression of a genetically acquired trait. The balance between genes and environment in disease expression is variable, but maintaining normal weight 
Table I Diagnostic criteria of the MS, according to the most popular proposals (National Cholesterol Education Program, International Diabetes Federation, and the Joint Interim Statement of several International Associations and Agencies)

\begin{tabular}{|c|c|c|c|}
\hline \multirow[t]{2}{*}{ Criteria for diagnosis } & \multirow{2}{*}{$\begin{array}{l}\text { NCEP }(\text { ATP-III) } \\
\text { Any three of the } \\
\text { following }\end{array}$} & \multirow{2}{*}{$\begin{array}{l}\text { IDF }^{4} \\
\text { Visceral obesity + two } \\
\text { of the remaining }\end{array}$} & \multirow{2}{*}{$\begin{array}{l}\text { Joint Interim Statement }{ }^{5} \\
\text { Any three of the } \\
\text { following }\end{array}$} \\
\hline & & & \\
\hline Visceral obesity & $\begin{array}{l}\text { Waist circumference }>102 \mathrm{~cm}(\mathrm{M}) \\
\text { or }>88 \mathrm{~cm}(\mathrm{~F})\end{array}$ & $\begin{array}{l}\text { Waist circumference } \geq 94 \mathrm{~cm} \\
(\mathrm{M}) \text { or } \geq 88 \mathrm{~cm}(\mathrm{~F})^{\mathrm{a}}\end{array}$ & $\begin{array}{l}\text { Waist circumference } \geq 94 \mathrm{~cm} \\
(\mathrm{M}) \text { or } \geq 88 \mathrm{~cm}(\mathrm{~F})^{\mathrm{a}}\end{array}$ \\
\hline Atherogenic dyslipidemia & $\begin{array}{l}\text { HDL-Chol }<40 \mathrm{mg} / \mathrm{dL}(\mathrm{M}) \\
\text { or }<50 \mathrm{mg} / \mathrm{dL}(\mathrm{F})\end{array}$ & $\begin{array}{l}\text { HDL-Chol }<40 \mathrm{mg} / \mathrm{dL}(\mathrm{M}) \\
\text { or }<50 \mathrm{mg} / \mathrm{dL}(\mathrm{F})\end{array}$ & $\begin{array}{l}\text { HDL-Chol }<40 \mathrm{mg} / \mathrm{dL}(\mathrm{M}) \\
\text { or }<50 \mathrm{mg} / \mathrm{dL}(\mathrm{F})\end{array}$ \\
\hline & $\begin{array}{l}\text { Triglycerides } \geq 150 \mathrm{mg} / \mathrm{dL} \\
\text { or drug-treated }\end{array}$ & $\begin{array}{l}\text { Triglycerides } \geq 150 \mathrm{mg} / \mathrm{dL} \\
\text { or drug-treated }\end{array}$ & $\begin{array}{l}\text { Triglycerides } \geq 150 \mathrm{mg} / \mathrm{dL} \\
\text { or drug-treated }\end{array}$ \\
\hline Altered glucose regulation & $\begin{array}{l}\text { Blood glucose } \geq 110 \mathrm{mg} / \mathrm{dL} \\
\text { or treated for diabetes }{ }^{\mathrm{b}}\end{array}$ & $\begin{array}{l}\text { Blood glucose } \geq 100 \mathrm{mg} / \mathrm{dL} \\
\text { or treated for diabetes }\end{array}$ & $\begin{array}{l}\text { Blood glucose } \geq 100 \mathrm{mg} / \mathrm{dL} \\
\text { or treated for diabetes }\end{array}$ \\
\hline Elevated arterial pressure & $\begin{array}{l}\text { Arterial pressure } \geq 130 / 85 \mathrm{mmHg} \\
\text { or treated for hypertension }\end{array}$ & $\begin{array}{l}\text { Arterial pressure } \geq 130 / 85 \mathrm{mmHg} \\
\text { or treated for hypertension }\end{array}$ & $\begin{array}{l}\text { Arterial pressure } \geq 130 / 85 \\
\mathrm{mmHg} \text { or treated for hypertension }\end{array}$ \\
\hline
\end{tabular}

Notes: aThese cutoffs are valid for Caucasians. Different cutoffs are reported for individuals of different ethnic origin; 'Later reduced to II 0 mg/dL.

Abbreviations: NCEP, National Cholesterol Education Program; IDF, International Diabetes Federation; ATP-III, Adult Treatment Panel III.

and practicing physical activity remain the primary and most effective prevention strategy. ${ }^{14}$ Similarly, treatment should be based on the promotion of effective weight loss and physical exercise, but attempts at engaging patients in healthy lifestyles and at maintaining the results require specific strategies. ${ }^{14}$ Patients' adherence to nutritional prescription and motivation to practice daily physical activity progressively reduce in the course of time and with treatment length, ${ }^{15}$ and metabolic improvements rapidly vanish with weight regain. Long-term lifestyle modification strategies are necessary, and behavioral procedures represent the most effective nonsurgical approach. ${ }^{16}$

In this article, we address the following topics: i) the role of lifestyle modification in the management of MS, ii) the principles and the main strategies of lifestyle modifications based on behavior therapy, and iii) the new frontiers of lifestyle modification programs.

\section{The role of lifestyle modification in the management of MS}

Weight reduction represents the principal goal of most intervention studies on MS. There is complete agreement that weight loss is associated with significant improvements in the clinical abnormalities of MS, including blood glucose, lipid profile, and blood pressure, ${ }^{17,18}$ and even a moderate weight loss ( $7 \%$ reduction) in 4 weeks can improve the metabolic profile, despite the persistence of a high body mass index (BMI). ${ }^{19}$ However, the greater the BMI loss, the larger are the metabolic improvements.

In a 2-year study, 41 obese patients were assigned to a long-term diet and lifestyle modification therapy. ${ }^{20}$ Two-thirds of patients who achieved a weight loss of $10 \%$ or more did no longer meet the diagnostic criteria of MS, whereas in patients who lost $<10 \%$, the prevalence of MS remained high $(81 \%)$.

Lifestyle modifications are also desirable in subjects who have only one or two criteria of MS, not the full-blown disorder. In the large US Diabetes Prevention Program (DPP), the effects of lifestyle intervention have been investigated in more than 3000 participants with impaired glucose tolerance. ${ }^{21}$ The patients in the intervention group were allocated to an intensive lifestyle intervention (including a low-calorie, low-fat diet and weight loss) or to the metformin therapy ( $850 \mathrm{mg}$ three times daily.). MS incidence was reduced by $41 \%$ in the lifestyle group $(P<0.001)$ and by $17 \%$ in the metformin group $(P=0.03)$ compared with the placebo arm. Among participants who already met the criteria for MS at baseline, 38\% in the lifestyle group, $23 \%$ in the metformin group, and $18 \%$ in the placebo group no longer had the syndrome after a mean follow-up of 3.2 years. This demonstrates that lifestyle changes can, by themselves, reverse the metabolic abnormalities of MS. Similarly, the effects of lifestyle modification have been measured in the Finnish Diabetes Prevention Study. ${ }^{22}$ A cohort of 522 middleaged, overweight subjects with impaired glucose tolerance was randomized either to a usual care control group or to an intensive lifestyle intervention group. The control group received general dietary and exercise advice at baseline and had a yearly medical examination. The subjects in the intervention group received additional individualized dietary counseling from a nutritionist. They were also offered circuittype resistance training sessions and advised to increase overall physical activity. After 3 years, the intervention produced significantly larger effects on weight loss, dietary 
fat intake, moderate-to-severe leisure time physical activity, fasting glucose and lipid concentrations, ${ }^{22}$ and the incidence of diabetes was significantly reduced in comparison to controls ( $11 \%$ versus $23 \%, P<0.001){ }^{23}$ The intervention program was more intensive during the first year, when the changes in clinical characteristics were particularly large. In a secondary analysis, ${ }^{24}$ after a mean follow-up of 3.9 years, the intervention group reached a significant reduction in the prevalence of MS and visceral obesity compared to the control group. When compared to the results of the DPP study, in the Diabetes Prevention Study, the prevalence of MS in the control group tended to be lower, indicating that the 'mini-intervention' carried out in the control arm had some effect on the occurrence of MS.

In addition, the macronutrient composition of diet, not only the caloric deficit, may be important in the management of MS. In the SUN prospective cohort, ${ }^{25}$ a Mediterranean-style diet (high consumption of fruit, vegetables, legumes, grain, moderate alcohol intake, a moderate-to-low consumption of dairy products and meats/meat products, and a high monounsaturated-to-saturated fat ratio) was inversely associated with the cumulative incidence of MS. In the PREMIER study, ${ }^{26}$ the Dietary Approaches to Stop Hypertension diet (rich in fruit, vegetables, and low-fat dairy foods, and low in saturated and total fat intake) plus lifestyle interventions improved the metabolic parameters, particularly blood pressure.

In the treatment of MS, physical activity has a pivotal role. Cardiorespiratory fitness was reported to modulate the relationship between MS and fatal events, providing a strong protective effect against all-cause and cardiovascular mortality. ${ }^{27,28}$ The amount and the intensity of physical exercise regulated the circulating levels of lipids and other metabolic abnormalities responsible for cardiovascular risk. ${ }^{29}$ When combined with diet, physical activity exerted a greater effect compared with studies where either approach is practiced alone. ${ }^{30}$ In particular, adding aerobic exercise training to nutritional weight-reducing approach resulted in many more cases resolving (95\% versus $75 \%$ ) or improving (adjusted odds ratio, 3.68) MS compared to diet alone. ${ }^{31}$

The intensity of physical activity required to improve metabolic parameters is not defined. Even a low-intensity exercise training for a 2-month period improved some metabolic abnormalities, ${ }^{32}$ but an exercise dose-response was reported on the components of MS. ${ }^{33}$ Several studies confirmed that higher levels of physical activity are associated with lower prevalence and incidence of MS and cardiovascular risk factors in cross-sectional and prospective studies. ${ }^{34-36}$ In a recent analysis of the National Health and Nutrition Examination
Survey data, ${ }^{37}$ maintaining an active lifestyle, as assessed by the number of daily steps measured by an accelerometer, reduced the prevalence of MS and cardiovascular risk factors.

In summary, lifestyle modification programs are necessary to maintain metabolic changes in the long period, and such programs should always address both nutritional treatment and physical activity. ${ }^{38,39}$

\section{Principles and main strategies of lifestyle modifications based on behavior therapy}

Behavior therapy has been designed to provide patients with a set of principles and techniques to modify their eating and activity habits. ${ }^{40}$ Originally, the treatment was exclusively based on the learning theory (ie, behaviorism). The theory postulates that the behaviors causing obesity (excess eating and low exercising) are largely learnt and therefore could be modified or relearnt. ${ }^{41-43}$ The theory also postulated that positive changes in eating and exercising can be achieved by modifying the environmental cues (antecedents) and the reinforcements of these behaviors (consequences). ${ }^{43}$ The intervention was later integrated with cognitive strategies (eg, problem solving and cognitive restructuring) and with specific recommendations on diet and exercise. ${ }^{44}$ The treatment is different from typical psychotherapy. The aim is not to treat a psychiatric disorder, but rather to change eating and exercise behaviors. In addition, lifestyle intervention does not address the potential causes of the problematic behaviors, but it is focused to teach skills to change them. ${ }^{40}$

\section{How to deliver lifestyle modification treatment}

In research settings, lifestyle modification treatments have been delivered in individual sessions (as was in the DPP) ${ }^{45}$ or in groups of $\sim 10-20$ participants ${ }^{46}$ or in groups combined with individual sessions (as in the Look AHEAD study). ${ }^{47}$ Outside research settings, lifestyle modification treatment should be delivered by a multidisciplinary team composed of physicians and nonphysician health professionals, such as dieticians or professionals with a master degree in exercise physiology, behavioral psychology, or health education. ${ }^{48}$ Within these multidisciplinary teams, physicians should limit their intervention to the initial assessment, the management of medical complication, the engagement in lifestyle modification treatment, and in a periodic medical evaluation; nonphysician health professionals should be actively involved in the delivery of lifestyle modification treatment. 
Although both individual and group treatment strategies are effective, a study found that participants who were randomized to receive group-based therapy lost significantly more weight than those who were treated individually. ${ }^{49}$ Despite the benefits of group treatment, several clinicians believe that individual contact is critical to keep patients in long-term treatment. ${ }^{47}$ The development of a trusting relationship between clinicians and patients is considered as a safety net for participants who stop attending group sessions regularly, a common event after the first 6-12 months. ${ }^{50,51}$

\section{Frequency and duration of lifestyle modification treatment}

Lifestyle modification programs generally offer patients with obesity an intensive first phase, consisting of 16-26 weekly sessions. ${ }^{46,52}$ After 6 months, weight loss tends to reach a plateau, irrespective of treatment strategies, excluding bariatric surgery, ${ }^{52,53}$ and weekly treatment of up to 1 year produces only marginally greater weight loss than that achieved in 6 months. ${ }^{54}$ Unfortunately, no definite data are available about the optimal duration and intensity of the weight maintenance phase. A few studies showed that group sessions delivered twice a month for 1 year after the weight loss phase facilitated the weight loss maintenance, while retaining patients in active treatment. ${ }^{52,55}$ However, continuous care up to 3 years produced long-term weight loss only in a subgroup of obese patients and was associated with a high rate of attrition. ${ }^{56}$ With too intensive models, most patients tend to experience therapy 'burnout', ${ }^{54}$ particularly when they reach the weight loss plateau, and monotonous sessions favor the discontinuation of treatment. ${ }^{46}$ Noteworthy, not all dropouts should be considered treatment failures. Patients satisfied with the results obtained with treatment and those who were confident to lose additional weight without professional help were shown to maintain an even larger mean weight loss than continuers. ${ }^{56}$

\section{Strategies to engage patients in lifestyle modification}

Some of the key principles and strategies to engage patients in lifestyle modification, derived from motivational interviewing, ${ }^{57,58}$ are listed below:

- Conceptualization of motivation. Motivation is a dynamic entity waxing and waning as a function of shifting personal, cognitive, behavioral, and environmental determinants. ${ }^{59}$ This means that patients' motivation may require continuous attention, not only during the engaging process, but also in the course of treatment. ${ }^{60}$

- Collaborative therapeutic style. Clinicians should adopt a collaborative therapeutic style as opposed to a confrontational approach. ${ }^{61}$ The collaborative style of cognitive behavior therapy has been considered as one of the main reasons for its higher success compared to other interventions to engage patients with resistance. ${ }^{62}$

- Acceptance and change. Clinicians should validate patients' experience within the framework of a balance between acceptance and change, firmness, and empathy. ${ }^{63}$

- Functional analysis. Clinicians should make a functional analysis of the pros and cons of changing lifestyle because change is facilitated by communicating in a way that elicits the person's own reasons for and the advantages of change. ${ }^{57}$

- Roll with resistance. Clinicians should not address resistance with confrontation, but with a collaborative evaluation of the variables involved in maintaining the unhealthy lifestyle. ${ }^{57}$

- Support self-efficacy. Self-efficacy refers to a person's belief that he/she is capable of keeping a specific behavior; ${ }^{64}$ it plays an important role in achieving health behavior change. ${ }^{65}$ In the evaluation interview, clinicians should promote self-efficacy by raising the hope that lifestyle changes can be attained. Later, during the program, self-efficacy should be promoted by designing an individualized eating and physical activity program that patients are confident to stick to. ${ }^{66}$

- Be sensitive to stigma against individuals with obesity. Stigma influences the decision of patients with obesity to start treatment. ${ }^{67}$ To prevent stigma, clinicians should recognize that obesity and MS are medical conditions and not the product of lack of willpower and treat patients with respect and support. ${ }^{67}$

- Educate patients. Clinicians should inform patients of the negative aspects of unhealthy lifestyles and the benefits of engaging in healthy behavior on the management of MS. Table 2 shows the main topics to cover when educating patients on MS and lifestyle modification. A strategy to promote patients' engagement in treatment is also giving detailed information about aims, duration, organization procedures, and the results of lifestyle modification, using written material. ${ }^{16}$ In reluctant patients, it might be helpful to propose treatment as a sort of experiment, with a possible return to the old habits in the absence of benefits. ${ }^{68}$ 
Table 2 Main topics to cover when educating patients on MS and on lifestyle modification

\section{Definition and diagnosis}

The MS is a cluster of conditions that increase the risk of developing vascular disease (heart disease, strokes, and peripheral vascular disease) For diagnosis, see Table I

\section{Prevalence}

MS affects up to $25 \%$ of the population in the United States ${ }^{7}$ and $15 \%$ of the population in Europe 9

It increases with age ( $<10 \%$ in individuals aged $20-29,20 \%$ in individuals aged $40-49$, and $45 \%$ in individuals aged $60-69)^{7}$

The 'obesity epidemic' is considered the main factor responsible for the increasing prevalence of $\mathrm{MS}^{6}$

\section{Causes}

It is linked to insulin resistance.' The causes of insulin resistance have not yet been completely clarified. It probably involves a variety of genetic and environmental factors. Both being overweight and inactive contribute to the disease state

\section{Consequences}

MS increases the risk of developing type 2 diabetes " and CVD and the risk for CVD mortality ${ }^{10}$

Other conditions that are associated with MS are, notably, polycystic ovary syndrome, fatty liver, cholesterol, gallstones, asthma, sleep disturbances, and some forms of cancer ${ }^{6}$

\section{Management}

Weight loss with lifestyle modification (hypocaloric diet, increased physical activity, and cognitive behavior therapy to help patients modify eating and activity habits) is the key procedure to manage MS. ${ }^{2}$ Research data indicate that a lifestyle intervention produce a marked reduction in the prevalence of MS and a decline of body weight, waist circumference, fasting glucose, triglycerides, and blood pressure. ${ }^{21}$ The treatment may be delivered in groups and/or individually by a multidisciplinary team trained in lifestyle modification, which includes a registered dietitian, a behavioral psychologist, and an exercise specialist, coordinated by a physician. It includes weekly sessions for the first 6 months, followed by two sessions a month in the following 6 months

Specific treatment of lipid (eg, hypertriglyceridemia) and nonlipid risk factors (eg, hypertension and hyperlycemia) may be added to the lifestyle modification $^{2}$

Abbreviation: CVD, cardiovascular disease.

\section{Dietary recommendations}

Lifestyle modification programs recommend a low-calorie diet, and their basic principles are reported in Table $3 .{ }^{16}$ Diets are intended to induce a caloric deficit of 500-1000 kcal/ day, and able to promote a weight loss of $0.5-1.0 \mathrm{~kg} / \mathrm{week}$. Very-low-calorie diets, with a calorie content $\leq 800 \mathrm{kcal} /$ day, are no longer recommended because, despite producing greater initial weight losses, they require medical monitoring and nutritional supplementation and have no advantages on long-term weight loss. ${ }^{50}$ Recently, several randomized controlled trials found that low-carbohydrate diets (ie, $<30 \mathrm{~g} /$ day) produced greater initial weight reductions than the more traditional low-calorie diets ( 1000-1200 kcal/day) described in Table $3 .^{69-71}$ However, weight loss, metabolic outcomes,
Table 3 Practical recommendations for diet and physical exercise in lifestyle modification programs

\section{Dietary recommendations ${ }^{16}$}

$1000-1200 \mathrm{kcal} /$ day for overweight women, and 1200-1600 kcal/day for overweight men and heavier for more active women

The diet should provide $\geq 55 \%$ calories from carbohydrates, $\leq 30 \%$ from lipids ( $7 \%-10 \%$ from saturated fats), and $\sim 15 \%$ from proteins

Total calories should be moderately increased according to the daily amount of physical activity

Diets are designed to create a calorie deficit of $500-1000 \mathrm{kcal} / \mathrm{day}$, producing a weight loss of $0.5-1.0 \mathrm{~kg} /$ week

\section{Physical exercise recommendations ${ }^{77}$}

Engage in moderate-to-vigorous exercise for at least $60 \mathrm{~min}$ on most days (at least 5 days/week)

Walking may be the favorite exercise, as unstructured exercise may be included in routine daily activities

Check the baseline number of steps by a pedometer, then add 500 steps at 3-day intervals to a target value of 10,000-12,000 steps/day Jogging (20-40 min/day), biking, or swimming (45-60 min/day) may replace walking

Physical exercise is intended to produce a calorie deficit of at least $400 \mathrm{kcal} /$ day, favoring weight loss, maintaining muscle mass, and preventing weight cycling

Notes: The aim of behavior therapy is to provide patients with cognitive and behavioral skills to modify their lifestyle. Accordingly, these recommendations should not be intended as prescriptions, but should be tailored on patients' preferences.

and dietary intake are no longer different after 36 months. ${ }^{72}$ These data indicate that the real problem to face with dietary recommendation is not to identify the optimum macronutrient composition but the adherence to dietary modification in the long term.

Adherence may be enhanced by increasing diet structure and limiting food choices, thereby reducing temptation and the potential mistakes on calculating energy intake. ${ }^{40}$ A strategy to increase the diet structure is to provide patients with meal plans, grocery lists, menus, and recipes. ${ }^{73}$ Support for this strategy derives from a study showing that the provision of both low-calorie food (free of charge or subsidized) and structured meal plans resulted in significantly greater weight loss than a diet with no additional structure. ${ }^{73}$

Another effective strategy to increase dietary adherence is meal replacements. A meta-analysis of six controlled trials found that liquid meal replacement determines a 3-kg greater weight loss than that produced by conventional diets. ${ }^{74}$ Meal replacement helps patients overcome some problems that occur when consuming conventional food diets (ie, underestimation of calorie intake, difficulties in estimating portion sizes, macronutrient composition, calorie content, and in recalling the consumed food), and simplify food choices ${ }^{46}$ The use of portion-controlled servings of conventional food is another effective strategy to facilitate dietary adherence and weight loss. ${ }^{75,76}$ 


\section{Exercise recommendations}

An initial assessment is needed to determine the current level of physical activity in individual patients. It is clinically useful to start asking patients how they judge their present level of physical activity and whether they believe that it is adequate to lose or maintain body weight. If, as usual, patients report to be sedentary, the following step is asking why and whether there are physical or logistical barriers to exercise (eg, arthritis and time constraints).

Clinicians should evaluate which type of activity is feasible for patients, considering the barriers (see above) that can prevent a successful increase in physical activity. Accordingly, they should assist patients in developing a physical activity plan based on the initial assessment. Any type of physical activity should be encouraged.

Lifestyle modification programs recommend a moderate-to-vigorous exercise for at least $60 \mathrm{~min}$ on most days (Table 3). ${ }^{51,77}$ Lifestyle activity should be increased slowly in intensity and duration (by $5 \mathrm{~min} / \mathrm{session} /$ week), starting from a low-intensity exercise ( $\sim 3$ metabolic equivalent) in sedentary subjects, to avoid excessive fatigue, muscle pain, strains, or injuries. ${ }^{45,47}$ Patients should be encouraged to register their baseline physical activity or to check their baseline number of steps by a pedometer. Whenever brisk walking is chosen as the preferred activity, they should be instructed to add 500 steps at 3-day intervals to a target value of $10,000-12,000$ steps/day. ${ }^{16,78}$ Although aerobic exercise may be considered as the preferred activity, resistance exercise and strength training should also be considered as effective options according to individual preferences. The presence of medical comorbidities (eg, hypertension, cardiovascular disease, MS, and diabetes) could contraindicate strength training and may indicate additional medical workup, including exercise testing and/or appropriate medical supervision during exercise.

Exercise adherence, contrary to dietary adherence, increases with less structure. ${ }^{40}$ For example, patients engage in more physical activity when instructed to do so on their own at home than when asked to attend on-site, supervised, group-based exercise sessions. ${ }^{79}$ In addition, increasing lifestyle activity (eg, using stairs rather than elevators, walking rather than riding or using the car, and reducing the use of labor-saving devices) determines similar weight loss, but greater weight maintenance than structured, programmed activity. ${ }^{80-82}$ Finally, prescribing multiple short bouts (10 min each) rather than one long session may help patients accumulate more minutes of exercise. In summary, these data suggest that decreasing the structure of exercising probably reduces those barriers that inhibit exercise (eg, lack of time or financial resources). ${ }^{40}$

\section{Behavioral procedures}

\section{Self-monitoring}

The core procedure of the lifestyle modification treatment is based on self-monitoring of food intake, physical activity, and body weight $;{ }^{83}$ the larger the use of self-monitoring, the larger the amount of weight loss. ${ }^{84}$

Patients seeking to lose weight, in particular those who report difficulties in losing weight, underestimate their calorie intake by almost $50 \%{ }^{85}$ It is, therefore, essential to help patients improve their ability in estimating food intake by using measurement tools (such as cups, spoons, and food scales) and nutrition fact labels and manuals with the calorie content of food. ${ }^{40}$ Practical in-session exercises are useful for this purpose. Patients are invited to register, in a monitoring sheet, the time, the amount, the type, and the calorie content of the food and beverages they are planning to consume and later check during meals if they respect their plans. Any change should be noted in the food diary, and the amount of calorie intake should be recalculated. 'Real time' monitoring is a strategy that may help patients interrupt behaviors that are automatic and out of control. ${ }^{86}$

Physical activity can be recorded on the same monitoring sheet in minutes (of programmed activity) and/or steps (of lifestyle activity), using a pedometer, with the intent to reach at least 10,000 steps/day. ${ }^{40}$ Patients interested in having a more precise measurement of their daily energy expenditure may use an accelerometer, which measures total expenditure, the energy expenditure in physical activity, the duration and the levels (in metabolic equivalent of task) of physical activity and sleeping time.

Patients may also benefit from recording activities, moods, and thoughts associated with eating and exercising. This information may help identify obstacles to behavior change. Self-monitoring records can also be used to provide information to identify contingencies that can be targeted for intervention. ${ }^{40}$

Patients are also encouraged to check their weight regularly (eg, once a week), because frequent checking of weight is associated with better long-term weight maintenance, ${ }^{87}$ and to record their weight in a weight graph to assess their weight trend. Patients are encouraged to discuss the interpretation of weight change with their therapists during the group or the individual sessions. The weighing procedure has a number 
of purposes. First, it provides a good opportunity to educate patients about their weight, about body weight in general, and how to interpret the number on the scales, which otherwise they are prone to misinterpret. It is important to educate patients that each reading is subjected to error, mainly due to variation in the hydration state. For this reason, they need to focus on what happened over the past 4 weeks to distinguish weight changes from natural fluctuations. Second, weighing stimulates patients to maintain a lifestyle oriented to weight control. Third, regular weighing may help patients address two problematic behaviors with a negative influence on lifestyle modification adherence: excessive weight checking and avoidance of weight checking ${ }^{83}$ Patients with excessive weight checking (eg, several times a day) may reduce their effort to maintain a lifestyle focused on weight control if they misinterpret insignificant day-to-day weight oscillation as an increase. On the other hand, weight checking avoidance makes it impossible to test weight changes.

\section{Goal setting}

Patients entering lifestyle modification programs are encouraged to set specific and quantifiable weekly goals (ie, increasing physical activity by 1000 steps/week or eating only at meals), which should be realistic and moderately challenging. ${ }^{40} \mathrm{Goal}$ achievement is associated with a sense of accomplishment, which is reinforcing and enhances self-efficacy, ${ }^{48}$ a construct associated with long-term weight loss. ${ }^{56}$

Particular attention should be paid to patients' weight loss expectation, since higher weight loss expectations are associated with attrition. ${ }^{88} \mathrm{~A}$ few data indicate that encouraging participants to seek only a modest initial weight loss does not facilitate weight maintenance and produces a lower weight loss than standard treatment. ${ }^{89}$ In the initial phase of treatment, it is more useful to have patients focus on weekly weight loss (eg, losing from $1 / 2$ to $1 \mathrm{~kg}$ per week) and to detect and promptly address any warning sign of weight loss dissatisfaction, thus minimizing the risk of attrition. ${ }^{88}$ In our clinical experience, unrealistic weight loss expectations may be easily changed later when patients have reached some intermediate goals and the rate of weight loss is declining. Specific strategies to change weight goals have been recently described in the modern cognitive behavioral treatments of obesity. ${ }^{83} \mathrm{~A}$ crucial aspect favoring the modification of unrealistic weight goals is the development of a trusting and collaborative clinician-to-patient relationship. ${ }^{88}$ This is also a key factor to avoid the sense of abandonment that patients report as one of the main reasons of attrition. ${ }^{90}$

\section{Stimulus control}

These procedures are based on the principles of classical and operant conditioning. Stimulus control is aimed at modifying the environment (ie, external eating cues) to make it more conductive to choices supporting changes in eating and exercising. Patients should be instructed both to remove triggers of excessive eating (eg, keeping tempting food out of sight or avoiding buying it) and to increase positive cues for exercising (eg, lay out exercise clothes before going to bed) and for desirable behavior (eg, putting the food sheet on the table to facilitate its real-time compilation during eating). Stimulus control may also be used to reinforce the adherence to eating control and exercising by establishing a reward system (eg, encouraging patients to set weekly behavioral goals and to reward themselves in case of achievement, but not through food or inactivity). ${ }^{40}$ Encouraging patients to use cognitive rewards (eg, 'I've been OK, 'I'm doing great,' and 'I have the ability to lose weight and to have an active lifestyle') once they reach their lifestyle goals it may also help patients reduce their frustration associated with limited weight loss and strengthen their confidence in controlling body weight and maintaining a healthy lifestyle. Positive reinforcements may also be used by clinicians, who should congratulate the patients on every success they achieve and should never criticize failures. ${ }^{91}$ Criticism may produce guilt and loss of self-confidence, leading to attrition. An unconditional acceptance of patients' behavior and a problem-solving approach to cope with barriers will preserve the clinician-patient relationship. This approach will also help patients understand that the long-term success in weight management is related to a set of skills rather than to willpower.

Stimulus control may also be facilitated by the involvement of significant others. ${ }^{92}$ With the consent of patients, clinicians should involve significant others in the treatment program to create the 'optimum' environment for patients' change. The needs vary from patient to patient, but generally include planning together a written shopping list, eating the same foods, exercising together, creating a relaxed environment, and reinforcing patients' positive behaviors.

\section{Alternative behaviors}

This procedure is used to manage internal eating cues (eg, emotional stimuli). Patients are trained to identify these cues and to replace eating cues with alternative behaviors. Any alternative behavior works better if it is incompatible with eating (eg, writing, knitting, housekeeping, exercising, and taking a bath). Other behaviors (eg, listening to music or 
reading) might not be appropriate, as people can easily eat and listen to music or read a book simultaneously. ${ }^{40}$

\section{Cognitive procedures}

Proactive problem solving

Proactive problem solving is used to address events that hinder lifestyle weight control adherence. The typical problemsolving approach includes five steps. ${ }^{93}$ Step 1 encourages patients to detail the problem and the chain of events (ie, situations) that preceded the problem. Step 2 helps patients brainstorm any possible solution. Step 3 suggests patients list the pros and cons for each potential solution. In step 4, patients should choose the best option on the basis of the previous analyses to be implemented for a fixed amount of time. Finally, during step 5, the patients evaluate the results achieved. If the solution fails, the process should be repeated.

Initially, it is recommended to practice problem solving in the session with the clinician, encouraging the patient to take the lead whenever possible. As homework, patients should be asked to practice their own problem-solving skills, looking out for events that would be liable to trigger changes in their eating or exercising and addressing them using the problem-solving procedure. Specifically, once patients identify a problem, they should write 'Problem' in the right-hand column of the monitoring record sheet and then turn the sheet over and write out the problem-solving steps. Patients should be advised against solving the problem mentally, as this is much less effective. The emphasis should be on helping patients acquire the ability to address or forestall events that would otherwise trigger changes in eating or exercising. As it is important that problems are spotted early, patients should be encouraged to screen in advance for problems they will meet during the week. In this way, their problem solving becomes 'proactive. ${ }^{86}$

\section{Cognitive restructuring}

Cognitive restructuring is a technique used to help patients identify dysfunctional thoughts and cognitive distortions that interfere with their ability to maintain a lifestyle aimed at weight control and to replace them with more functional ones (see Figure 1) ${ }^{94,95}$ All-or-nothing thinking, in particular with regard to success or failure, is a common cognitive bias observed in patients during weight loss. ${ }^{40}$ In addition, for this activity, patients are recommended to practice cognitive restructuring during a session with therapists. Later, clinicians should give patients homework to practice cognitive restructuring every time they notice a tendency to decrease their efforts in lifestyle modification as a consequence of an event. Specifically, when patients identify a dysfunctional thought, they should write 'Dysfunctional thoughts' in the right-hand column of their monitoring sheet and then turn the sheet over and address it by writing out the cognitive restructuring steps (see Figure 1).

\section{New frontiers of lifestyle modification programs}

At 3- to 5-year follow-up, $70 \%-80 \%$ of patients treated with lifestyle modification regained all the weight they had lost. ${ }^{96,97}$ These data underline the fact that the major problem of lifestyle modification treatment is weight loss maintenance in the long term. Unfortunately, the mechanisms accounting for weight regain have not been completely understood yet, but they seem extremely complex, including biological, social, behavioral,

(A) Event

Gained $1 / 2 \mathrm{~kg}$ this week

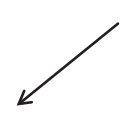

(B) Dysfunctional thoughts

"It is a failure; I will never be able to lose weight. I had better give up trying to lose weight"

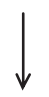

(C) Consequence

Reduced efforts

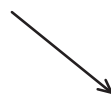

(B) Functional thoughts

"It is not a failure, but just a set back It is difficult to lose weight, but not impossible: I've done it before"

(C) Consequence

Increased efforts

Figure I An example of cognitive restructuring.

Notes: According to the cognitive model, the link between an activating event $\mathbf{A}$ ) and the emotional or behavioral consequence $\mathbf{C}$ ) is influenced by the belief $\mathbf{B}$ ) about the activating event. When the belief contains cognitive bias (eg, as all-or-nothing thinking) as in the scenario on the left, the consequence tends to be unfavorable. However, if the beliefs about that event have been adequately challenged and substituted with more functional thoughts, the consequences are more favorable (scenario on the right). ${ }^{94}$ 
and cognitive factors. Nevertheless, the observation that at least $20 \%$ of patients maintain all the amount of weight loss at 4-year follow-up ${ }^{98}$ indicates that weight loss maintenance is possible. In this section, we discuss three potential areas of intervention (biological, cognitive, and environmental) that might improve the long-term maintenance of weight loss.

\section{Combining lifestyle modification with pharmacotherapy}

One of the main factors implicated in the long-term failure of weight maintenance is the biological pressure to weight regain..$^{99}$ It is, therefore, rational to evaluate the effect of combining lifestyle modification with pharmacological therapies aimed to mitigate the biological pressure to weight regain. The available data suggest that this combined approach seems to improve both the amount of weight loss and the maintenance of weight lost. ${ }^{100}$ The enhancement of weight loss is also associated with marked improvements in several metabolic outcomes and risk factors of cardiovascular disease. ${ }^{101}$ Two medications - orlistat and sibutramine - are currently approved in the United States for long-term weight loss.

A randomized controlled trial comparing the effects of lifestyle modification and sibutramine $(15 \mathrm{mg} /$ day $)$ either alone or in combination found that there were no differences in weight loss at 1-year weight for participants who received group-based lifestyle modification alone versus those who received sibutramine alone. ${ }^{100}$ However, participants treated with group-based lifestyle modification and sibutramine achieved a 1-year weight loss nearly twice as large as that of either therapy alone. ${ }^{100}$ These data show that lifestyle modification and pharmacotherapy are equivalent when used separately, but additive when used in combination. Unfortunately, the preliminary analysis of the Sibutramine Cardiovascular Outcomes Trial, ${ }^{102}$ which assessed the safety of sibutramine in individuals with preexisting cardiovascular diseases or diabetes mellitus, showed a higher rate of cardiovascular disease events in the sibutramine group compared to placebo (11.4\% versus $10.0 \%)$. On the basis of these results, sibutramine was withdrawn from the European market in January $2010,{ }^{103,104}$ but it is still available in the United States.

The XENDOS (Xenical in the Prevention of Diabetes in Obese Subjects) randomly assigned 3305 participants to lifestyle plus placebo intervention or lifestyle changes plus orlistat who had a significant low cumulative incidence of type 2 diabetes and a greater weight loss than those treated only with lifestyle modification. ${ }^{105} \mathrm{~A}$ few cases of serious adverse hepatic effects (eg, cholestatic hepatitis and subacute liver failure) have been reported with the use of orlistat, prompting the FDA to issue an update on the safety of orlistat in September
2009. ${ }^{106}$ However, the drug can be still prescribed and can be also purchased over-the-counter at a lower dose $(60 \mathrm{mg})$.

Some combination therapies targeting multiple hypothalamic pathways that regulate appetite and body weight are currently under investigation, but very few data have so far been reported on their long-term safety and efficacy. ${ }^{107,108}$

\section{Addressing cognitive processes implicated in weight loss failure}

The National Weight Control Registry (NWCR) has intensively investigated individuals with long-term successful weight loss. ${ }^{109}$ The participants registered in the NWCR must have maintained a weight loss of $\geq 13.6 \mathrm{~kg}$ ( $\geq 30 \mathrm{lb}$ ) for at least 1 year, and on an average, they must have maintained a $32-\mathrm{kg}(70 \mathrm{lb})$ weight loss for 6 years. The principal behaviors reported by $\sim 3000$ NWCR participants were: ${ }^{109-111}$ i) selfmonitoring of food intake and body weight (at least once a week), ii) consuming a low-calorie (1300-1400 kcal/day) and low-fat diet ( $20 \%-25 \%$ of daily energy intake from fat), iii) eating breakfast every day, and iv) practicing regular physical activity to expend 2500-3000 kcal/week (eg, walking 4 miles/ day). However, the research has not clarified yet why some individuals stop practicing weight control behaviors after losing weight, while others maintain them.

As cognitive processes are involved in the maintenance of complex behaviors, such as eating and exercise, they are likely to play a key role in the process of weight regain or maintenance, ${ }^{112}$ but have been scarcely evaluated by research.

The cognitive processes implicated in weight loss and weight maintenance have been tested in the QUOVADIS study, a large observational study on the quality of life of obese patients seeking treatment at 25 medical centers certified by the Italian Health Service for the treatment of obesity. ${ }^{113}$ The study provided three main results. First, treatment attrition was associated with higher weight loss expectations. ${ }^{88}$ Second, the amount of weight loss was predicted by increased dietary restraint and reduced dietary disinhibition. ${ }^{114}$ Third, long-term weight maintenance ( $>3$ years) was observed in patients satisfied with the results achieved, or confident to control their body weight without additional professional help, ${ }^{56}$ a construct similar to the concept of self-efficacy, which is associated with greater adherence to physical therapy. ${ }^{115}$ These data suggest that including specific strategies to address cognitive obstacles to weight loss and weight maintenance could improve the long-term effectiveness of lifestyle modification interventions.

Two books have been recently published with a major focus on strategies addressing cognitive processes implicated 
in weight loss and maintenance, ${ }^{83,116}$ and some studies found that adding cognitive procedures to lifestyle modification is associated with better weight loss maintenance. ${ }^{117-121}$ However, a recent randomized control trial failed to observe a positive effect on long-term weight loss maintenance of a cognitive behavior intervention specifically designed to address the cognitive processes associated with weight regain. ${ }^{122}$

\section{General strategies at population level to facilitate lifestyle modification}

Lifestyle modification might have more chance to be more effective if supported by public health programs to change the 'toxic' environment promoting overeating and sedentary behaviors. ${ }^{123}$ Examples of a long list of possible interventions aimed at improving the dietary and lifestyle habits of the general population include i) modifying the urban design and favoring physical activity in the community (parks, sidewalks, and bike paths) and at school (physical fitness curricula), ii) regulating the aggressive economic policies promoting the purchase of processed foods, iii) increasing the opportunities for family interaction (eg, family gathering at meal time), iv) reducing the exposure of children to marketing of energy-dense, micronutrient-poor foods, v) preventing the collusion of schools in the sale of junk foods, vi) reducing the portion of the meals served in the restaurant, vii) teaching skills for preparing healthy food (implementing nutritional standards for food in school, preschool, and after-school programs; nutritional labeling of food; warning labels on 'junk food'), and viii) favoring the access of low-income ethnic and social groups to healthy food. ${ }^{124}$

\section{Conclusions}

Lifestyle modification plays a central role in the management of MS. Programs based on lifestyle modification have improved in the last few years; recent data show that a modest long-term weight loss is associated with a marked reduction of the incidence of type 2 diabetes $^{125}$ and the prevalence of MS. ${ }^{21}$ The promising results obtained with the inclusion of innovative procedures, such as combining lifestyle modification with pharmacotherapy, ${ }^{100}$ using meal replacement, ${ }^{74}$ setting higher physical activity goals, ${ }^{126}$ and long-term care, ${ }^{127}$ raise optimistic expectations for an effective treatment of obesity and MS with lifestyle modifications.

More research is needed to understand the negative phenomenon of weight regain. The key role of cognitive processes in the success/failure in weight loss and weight maintenance ${ }^{56,88,114}$ suggests that new cognitive procedures and strategies should be included in the traditional lifestyle modification programs, in order to help patients build a mind-set of long-term weight control. Lifestyle modification programs will be more effective if supported by public health programs to change the environment where patients live. Only through the synergy of individuals and a society global response, the maximum benefit for patients with MS can be achieved, thus reducing the burden of advanced disease and premature death. ${ }^{48}$

Finally, the positive results obtained by lifestyle modification programs in the management of MS should stimulate physicians to adopt a 'team approach.' General practitioners, as well as physicians working in metabolic units and treating patients with MS, should receive adequate training in cognitive behavioral therapy to engage patients in lifestyle modification. Engaged patients should then be referred to trained lifestyle counselors (eg, dieticians, psychologists, physical activity supervisors, and case managers) working closely with them, ideally in the same lifestyle modification unit, to implement the full lifestyle modification program.

\section{Acknowledgment}

The research of GM has received funding from the European Community's Seventh Framework Program (FP7/2007-2013) under grant agreement no. HEALTH-F2-2009-241762 for the project FLIP.

\section{Disclosure}

The authors report no conflicts of interest in this work.

\section{References}

1. Ferrannini E, Haffner SM, Mitchell BD, Stern MP. Hyperinsulinaemia: the key feature of a cardiovascular and metabolic syndrome. Diabetologia. 1991;34(6):416-422.

2. Expert Panel on Detection, Evaluation, and Treatment of High Blood Cholesterol in Adults. Executive summary of the third report of the National Cholesterol Education Program (NCEP) expert panel on detection, evaluation, and treatment of high blood cholesterol in adults (Adult Treatment Panel III). JAMA. 2001;285(19):2486-2497.

3. Grundy SM, Cleeman JI, Daniels SR, et al. Diagnosis and management of the metabolic syndrome: an American Heart Association/National Heart, Lung, and Blood Institute scientific statement. Circulation. 2005;112(17):2735-2752.

4. Alberti KG, Zimmet P, Shaw J. IDF Epidemiology Task Force Consensus Group. The metabolic syndrome-a new worldwide definition. Lancet. 2005;366(9491):1059-1062.

5. Alberti KG, Eckel RH, Grundy SM, et al. Harmonizing the metabolic syndrome: a joint interim statement of the International Diabetes Federation task force on epidemiology and prevention; National Heart, Lung, and Blood Institute; American Heart Association; World Heart Federation; International Atherosclerosis Society; and International Association for the Study of Obesity. Circulation. 2009;120(16):1640-1645.

6. Grundy SM, Brewer HB Jr, Cleeman JI, Smith SC Jr, Lenfant C. American Heart Association; National Heart, Lung, and Blood Institute. Definition of metabolic syndrome: report of the National Heart, Lung, and Blood Institute/American Heart Association conference on scientific issues related to definition. Circulation. 2004;109(3):433-438.

7. Ford ES, Giles WH, Dietz WH. Prevalence of the metabolic syndrome among US adults: findings from the third National Health and Nutrition Examination Survey. JAMA. 2002;287(3):356-359. 
8. Churilla JR, Fitzhugh EC, Thompson DL. The metabolic syndrome: how definition impacts the prevalence and risk in U.S. adults: 1999-2004 NHANES. Metab Syndr Relat Disord. 2007;5(4): 331-342.

9. Hu G, Qiao Q, Tuomilehto J, Balkau B, Borch-Johnsen K, Pyorala K. DECODE Study Group. Prevalence of the metabolic syndrome and its relation to all-cause and cardiovascular mortality in nondiabetic European men and women. Arch Intern Med. 2004;164(10): 1066-1076.

10. Lakka HM, Laaksonen DE, Lakka TA, et al. The metabolic syndrome and total and cardiovascular disease mortality in middle-aged men. JAMA. 2002;288(21):2709-2716.

11. Lorenzo C, Williams K, Hunt KJ, Haffner SM. Trend in the prevalence of the metabolic syndrome and its impact on cardiovascular disease incidence: the San Antonio Heart Study. Diabetes Care. 2006; 29(3):625-630.

12. Ford ES. The metabolic syndrome and mortality from cardiovascular disease and all-causes: findings from the National Health and Nutrition Examination Survey II Mortality Study. Atherosclerosis. 2004;173(2):309-314.

13. Levantesi G, Macchia A, Marfisi R, et al. Metabolic syndrome and risk of cardiovascular events after myocardial infarction. J Am Coll Cardiol. 2005;46(2):277-283

14. Magkos F, Yannakoulia M, Chan JL, Mantzoros CS. Management of the metabolic syndrome and type 2 diabetes through lifestyle modification. Annu Rev Nutr. 2009;29:223-256.

15. Wadden TA, Butryn ML, Wilson C. Lifestyle modification for the management of obesity. Gastroenterology. 2007;132(6) 2226-2238.

16. Clinical guidelines on the identification, evaluation, and treatment of overweight and obesity in adults-the evidence report. National Institutes of Health. Obes Res. 1998;6 Suppl 2:51S-209S.

17. Villareal DT, Miller BV 3rd, Banks M, Fontana L, Sinacore DR, Klein S. Effect of lifestyle intervention on metabolic coronary heart disease risk factors in obese older adults. Am J Clin Nutr. 2006;84(6): 1317-1323.

18. Phelan S, Wadden TA, Berkowitz RI, et al. Impact of weight loss on the metabolic syndrome. Int J Obes (Lond). 2007;31(9): 1442-1448.

19. Case CC, Jones PH, Nelson K, O'Brian Smith E, Ballantyne CM. Impact of weight loss on the metabolic syndrome. Diabetes Obes Metab. 2002;4(6):407-414.

20. Muzio F, Mondazzi L, Sommariva D, Branchi A. Long-term effects of low-calorie diet on the metabolic syndrome in obese nondiabetic patients. Diabetes Care. 2005;28(6):1485-1486.

21. Orchard TJ, Temprosa M, Goldberg R, et al. The effect of metformin and intensive lifestyle intervention on the metabolic syndrome: the Diabetes Prevention Program randomized trial. Ann Intern Med. 2005 142(8):611-619.

22. Lindstrom J, Louheranta A, Mannelin M, et al. The Finnish Diabetes Prevention Study (DPS): lifestyle intervention and 3-year results on diet and physical activity. Diabetes Care. 2003;26(12): 3230-3236.

23. Tuomilehto J, Lindstrom J, Eriksson JG, et al. Prevention of type 2 diabetes mellitus by changes in lifestyle among subjects with impaired glucose tolerance. N Engl J Med. 2001;344(18):1343-1350.

24. Ilanne-Parikka P, Eriksson JG, Lindstrom J, et al. Effect of lifestyle intervention on the occurrence of metabolic syndrome and its components in the Finnish Diabetes Prevention Study. Diabetes Care. 2008; 31(4):805-807.

25. Tortosa A, Bes-Rastrollo M, Sanchez-Villegas A, BasterraGortari FJ, Nunez-Cordoba JM, Martinez-Gonzalez MA. Mediterranean diet inversely associated with the incidence of metabolic syndrome: the SUN prospective cohort. Diabetes Care. 2007;30(11): 2957-2959.

26. Lien LF, Brown AJ, Ard JD, et al. Effects of PREMIER lifestyle modifications on participants with and without the metabolic syndrome. Hypertension. 2007;50(4):609-616.
27. Katzmarzyk PT, Church TS, Blair SN. Cardiorespiratory fitness attenuates the effects of the metabolic syndrome on all-cause and cardiovascular disease mortality in men. Arch Intern Med. 2004;164(10): 1092-1097.

28. Myers J, Prakash M, Froelicher V, Do D, Partington S, Atwood JE. Exercise capacity and mortality among men referred for exercise testing. $N$ Engl J Med. 2002;346(11):793-801.

29. Kraus WE, Houmard JA, Duscha BD, et al. Effects of the amount and intensity of exercise on plasma lipoproteins. $N$ Engl J Med. 2002; 347(19):1483-1492.

30. Anderssen SA, Carroll S, Urdal P, Holme I. Combined diet and exercise intervention reverses the metabolic syndrome in middle-aged males: results from the Oslo Diet and Exercise Study. Scand J Med Sci Sports. 2007;17(6):687-695.

31. Okura T, Nakata Y, Ohkawara K, et al. Effects of aerobic exercise on metabolic syndrome improvement in response to weight reduction. Obesity (Silver Spring). 2007;15(10):2478-2484.

32. Dumortier M, Brandou F, Perez-Martin A, Fedou C, Mercier J, Brun JF Low intensity endurance exercise targeted for lipid oxidation improves body composition and insulin sensitivity in patients with the metabolic syndrome. Diabetes Metab. 2003;29(5):509-518.

33. Johnson JL, Slentz CA, Houmard JA, et al. Exercise training amount and intensity effects on metabolic syndrome (from studies of a Targeted Risk Reduction Intervention through Defined Exercise). Am J Cardiol. 2007;100(12):1759-1766.

34. Carroll S, Dudfield M. What is the relationship between exercise and metabolic abnormalities? A review of the metabolic syndrome. Sports Med. 2004;34(6):371-418.

35. Katzmarzyk PT, Herman KM. The role of physical activity and fitness in the prevention and treatment of metabolic syndrome. Curr Cardiovasc Risk Rep. 2007;1(3):228-236.

36. Churilla JR, Zoeller RF Jr. Physical activity and the metabolic syndrome: a review of the evidence. Am J Lifestyle Med. 2008;2(2):118-125.

37. Sisson SB, Camhi SM, Church TS, Tudor-Locke C, Johnson WD, Katzmarzyk PT. Accelerometer-determined steps/day and metabolic syndrome. Am J Prev Med. 2010;38(6):575-582.

38. Jakicic JM, Otto AD. Physical activity considerations for the treatment and prevention of obesity. Am J Clin Nutr. 2005;82 Suppl 1: 226S-229S.

39. Johannsen DL, Redman LM, Ravussin E. The role of physical activity in maintaining a reduced weight. Curr Atheroscler Rep. 2007;9(6): 463-471.

40. Fabricatore AN. Behavior therapy and cognitive-behavioral therapy of obesity: is there a difference? JAm Diet Assoc. 2007;107(1):92-99.

41. Stuart RB. Behavioral control of overeating. Behav Res Ther. 1967;5(4):357-365.

42. Ferster CB, Nurnberger JI, Levitt EB. The control of eating. 1962. Obes Res. 1996;4(4):401-410.

43. Wing RR. Behavioral weight control. In: Wadden TA, Stunkard AJ, editors. Handbook of Obesity Treatment. New York, NY: Guildford Press; 2002:301-316.

44. Wadden TA, McGuckin BG, Rothman RA, Sargent SL. Lifestyle modification in the management of obesity. $J$ Gastrointest Surg. 2003;7(4):452-463.

45. The Diabetes Prevention Program Research Group. The Diabetes Prevention Program (DPP): description of lifestyle intervention. Diabetes Care. 2002;25(12):2165-2171.

46. Wadden TA, Butryn ML, Byrne KJ. Efficacy of lifestyle modification for long-term weight control. Obes Res. 2004;12 Suppl: $151 \mathrm{~S}-162 \mathrm{~S}$

47. Ryan DH, Espeland MA, Foster GD, et al. Look AHEAD (Action for Health in Diabetes): design and methods for a clinical trial of weight loss for the prevention of cardiovascular disease in type 2 diabetes. Control Clin Trials. 2003;24(5):610-628.

48. Bellentani S, Dalle Grave R, Suppini A, Marchesini G; Fatty Liver Italian Network. Behavior therapy for nonalcoholic fatty liver disease: the need for a multidisciplinary approach. Hepatology. 2008;47(2): 746-754. 
49. Renjilian DA, Perri MG, Nezu AM, McKelvey WF, Shermer RL, Anton SD. Individual versus group therapy for obesity: effects of matching participants to their treatment preferences. J Consult Clin Psychol. 2001;69(4):717-721.

50. Wadden TA, Foster GD, Letizia KA. One-year behavioral treatment of obesity: comparison of moderate and severe caloric restriction and the effects of weight maintenance therapy. J Consult Clin Psychol. 1994; 62(1):165-171.

51. Wing RR, Venditti E, Jakicic JM, Polley BA, Lang W. Lifestyle intervention in overweight individuals with a family history of diabetes. Diabetes Care. 1998;21(3):350-359.

52. Perri MG, Nezu AM, Patti ET, McCann KL. Effect of length of treatment on weight loss. J Consult Clin Psychol. 1989;57(3):450-452.

53. Buchwald H, Avidor Y, Braunwald E, et al. Bariatric surgery: a systematic review and meta-analysis. JAMA. 2004;292(14):1724-1737.

54. Wing RR, Blair E, Marcus M, Epstein LH, Harvey J. Year-long weight loss treatment for obese patients with type II diabetes: does including an intermittent very-low-calorie diet improve outcome? Am J Med. 1994;97(4):354-362.

55. Perri MG, McAllister DA, Gange JJ, Jordan RC, McAdoo G, Nezu AM. Effects of four maintenance programs on the long-term management of obesity. J Consult Clin Psychol. 1988;56(4):529-534.

56. Dalle Grave R, Melchionda N, Calugi S, et al. Continuous care in the treatment of obesity: an observational multicentre study. J Intern Med. 2005;258(3):265-273.

57. Miller WR, Rollnick S. Motivational Interviewing. 2nd ed. New York, NY: Guilford Press; 2002.

58. Wilson GT, Schlam TR. The transtheoretical model and motivational interviewing in the treatment of eating and weight disorders. Clin Psychol Rev. 2004;24(3):361-378.

59. Bandura A. Social Foundations of Thought and Action: A Social Cognitive Theory. Englewood Cliffs, NJ: Prentice-Hall; 1986.

60. Marlatt GA. Cognitive assessment and intervention procedures for relapse prevention. In: Marlatt GA, Gordon JR, editors. Relapse Prevention. New York, NY: Guilford Press; 1985:3-67.

61. Meichenbaum D, Gilmore J. Resistance: from a cognitive-behavioral perspective. In: Wachtel P, editor. Resistance: Psychodynamic and Behavioral Approaches. New York, NY: Plenum; 1982:133-156.

62. Guidano VF, Liotti G. Cognitive Processes and Emotional Disorders: a Structural Approach to Psychotherapy. New York, NY: Guilford Press; 1983.

63. Linehan MM. Skills Training Manual for Treating Borderline Personality Disorder. New York, NY: Guilford Press; 1993.

64. Bandura A. Self-efficacy: toward a unifying theory of behavioral change. Psychol Rev. 1977;84(2):191-215.

65. Strecher VJ, deVellis BM, Becker MH, Rosenstock IM. The role of self-efficacy in achieving health behavior change. Health Educ Q. 1986; 13(1):73-92.

66. di Loreto C, Fanelli C, Lucidi P, et al. Validation of a counseling strategy to promote the adoption and the maintenance of physical activity by type 2 diabetic subjects. Diabetes Care. 2003;26(2):404-408

67. Kushner RF. Roadmaps for Clinician Practice: Case Studies in Disease Prevention and Health Promotion. Assessment and Management of Adult Obesity: A Primer for Physicians. Chicago, IL: American Medical Association; 2003.

68. Garner DM, Vitousek K, Pike KM. Cognitive-behavioral therapy for anorexia nervosa. In: Garner DM, Garfinkel PE, editors. Handbook of Treatment for Eating Disorders. New York, NY: Guilford Press; 1997: $94-144$.

69. Brehm BJ, Seeley RJ, Daniels SR, D’Alessio DA. A randomized trial comparing a very low carbohydrate diet and a calorie-restricted low fat diet on body weight and cardiovascular risk factors in healthy women. J Clin Endocrinol Metab. 2003;88(4):1617-1623.

70. Foster GD, WyattHR, Hill JO, etal. A randomized trial of a low-carbohydrate diet for obesity. N Engl J Med. 2003;348(21):2082-2090.
71. Samaha FF, Iqbal N, Seshadri P, et al. A low-carbohydrate as compared with a low-fat diet in severe obesity. $N$ Engl J Med. 2003;348(21): 2074-2081.

72. Vetter ML, Iqbal N, Dalton-Bakes C, Volger S, Wadden TA. Long-term effects of low-carbohydrate versus low-fat diets in obese persons. Ann Intern Med. 2010;152(5):334-335.

73. Wing RR, Jeffery RW, Burton LR, Thorson C, Nissinoff KS, Baxter JE. Food provision vs structured meal plans in the behavioral treatment of obesity. Int J Obes Relat Metab Disord. 1996;20(1):56-62.

74. Heymsfield SB, van Mierlo CA, van der Knaap HC, Heo M, Frier HI. Weight management using a meal replacement strategy: meta and pooling analysis from six studies. Int J Obes Relat Metab Disord. 2003; 27(5):537-549.

75. Jeffery RW, Wing RR, Thorson C, et al. Strengthening behavioral interventions for weight loss: a randomized trial of food provision and monetary incentives. J Consult Clin Psychol. 1993;61(6):1038-1045.

76. Metz JA, Stern JS, Kris-Etherton P, et al. A randomized trial of improved weight loss with a prepared meal plan in overweight and obese patients: impact on cardiovascular risk reduction. Arch Intern Med. 2000;160(14):2150-2158.

77. US Department of Health and Human Services, U.S. Department of Agriculture. Dietary Guidelines for Americans, 2005. 6th ed. Washington, DC: US Government Printing Office; 2005.

78. Park S, Park H, Togo F, et al. Year-long physical activity and metabolic syndrome in older Japanese adults: cross-sectional data from the Nakanojo Study. J Gerontol A Biol Sci Med Sci. 2008;63(10): 1119-1123.

79. Perri MG, Martin AD, Leermakers EA, Sears SF, Notelovitz M. Effects of group- versus home-based exercise in the treatment of obesity. J Consult Clin Psychol. 1997;65(2):278-285.

80. Epstein LH, Wing RR, Koeske R, Ossip D, Beck S. A comparison of lifestyle change and programmed aerobic exercise on weight and fitness change in obese children. Behav Ther. 1982;13:651-665.

81. Andersen RE, Wadden TA, Bartlett SJ, Zemel B, Verde TJ, Franckowiak SC. Effects of lifestyle activity vs structured aerobic exercise in obese women: a randomized trial. JAMA. 1999;281(4):335-340.

82. Epstein J, Wiseman CV, Sunday SR, Klapper F, Alkalay L, Halmi KA. Neurocognitive evidence favors "top down" over "bottom up" mechanisms in the pathogenesis of body size distortions in anorexia nervosa. Eat Weight Disord. 2001;6(3):140-147.

83. Cooper Z, Fairburn CG, Hawker DM. Cognitive-Behavioral Treatment of Obesity: a Clinician's Guide. New York, NY: Guilford Press; 2003.

84. Baker RC, Kirschenbaum DS. Self-monitoring may be necessary for successful weight control. Behav Ther. 1993;24(3):377-394.

85. Lichtman SW, Pisarska K, Berman ER, et al. Discrepancy between self-reported and actual caloric intake and exercise in obese subjects. N Engl J Med. 1992;327(27):1893-1898.

86. Fairburn CG. Cognitive Behavior Therapy and Eating Disorders. New York, NY: Guildford Press; 2008.

87. O'Neil PM, Brown JD. Weighing the evidence: benefits of regular weight monitoring for weight control. J Nutr Educ Behav. 2005;37(6): 319-322.

88. Dalle Grave R, Calugi S, Molinari E, et al. Weight loss expectations in obese patients and treatment attrition: an observational multicenter study. Obes Res. 2005;13(11):1961-1969.

89. Foster GD, Phelan S, Wadden TA, Gill D, Ermold J, Didie E. Promoting more modest weight losses: a pilot study. Obes Res. 2004;12(8): 1271-1277.

90. Grossi E, Dalle Grave R, Mannucci E, et al. Complexity of attrition in the treatment of obesity: clues from a structured telephone interview. Int J Obes (Lond). 2006;30(7):1132-1137.

91. Wadden TA, Crerand CE, Brock J. Behavioral treatment of obesity. Psychiatr Clin North Am. 2005;28(1):151-170, ix.

92. Gruber KJ, Haldeman LA. Using the family to combat childhood and adult obesity. Prev Chronic Dis. 2009;6(3):A106. 
93. D'Zurilla TJ, Goldfried MR. Problem solving and behavior modification. J Abnorm Psychol. 1971;78(1):107-126.

94. Ellis A. Reason and Emotion in Psychotherapy. New York, NY: Stuart; 1962.

95. Beck AT. Cognitive Therapy and the Emotional Disorders. New York, NY: International Universities Press; 1976

96. Stalonas PM, Perri MG, Kerzner AB. Do behavioral treatments of obesity last? A five-year follow-up investigation. Addict Behav. 1984;9(2):175-183.

97. Wadden TA, Sternberg JA, Letizia KA, Stunkard AJ, Foster GD. Treatment of obesity by very low calorie diet, behavior therapy, and their combination: a five-year perspective. Int J Obes. 1989;13 Suppl 2: $39-46$.

98. Wing RR, Phelan S. Behavioral treatment of obesity: strategies to improve outcome and predictors of success. In: Eckel RH, editor. Obesity: Mechanisms and Clinical Management. Philadelphia, PA: Lippincott, Williams \& Wilkins; 2003:415-435.

99. Leibel RL, Rosenbaum M, Hirsch J. Changes in energy expenditure resulting from altered body weight. $N$ Engl $\mathrm{J}$ Med. 1995;332(10):621-628.

100. Wadden TA, Berkowitz RI, Womble LG, et al. Randomized trial of lifestyle modification and pharmacotherapy for obesity. $N$ Engl J Med. 2005;353(20):2111-2120.

101. Bray GA, Ryan DH. Drug treatment of the overweight patient. Gastroenterology. 2007;132(6):2239-2252.

102. Torp-Pedersen C, Caterson I, Coutinho W, et al. Cardiovascular responses to weight management and sibutramine in highrisk subjects: an analysis from the SCOUT trial. Eur Heart $J$. 2007;28(23):2915-2923.

103. European Medicines Agency. European Medicines Agency Recommends Suspension of Marketing Authorizations for Sibutramine; 2010. Available from: http://www.ema.europa.eu/pdfs/human/referral/ sibutramine/3940810en.pdf. Accessed 2010 Sep 9.

104. Finer N. Executive Steering Committee of the Sibutramine Cardiovascular Outcome Trial. Withdrawal of sibutramine. Editorial is judgment in advance of the facts. BMJ. 2010;340:c1346.

105. Torgerson JS, Hauptman J, Boldrin MN, Sjostrom L. XENical in the prevention of diabetes in obese subjects (XENDOS) study: a randomized study of orlistat as an adjunct to lifestyle changes for the prevention of type 2 diabetes in obese patients. Diabetes Care. 2004;27(1):155-161.

106. U.S. Food and Drug Administration. Early Communication About an Ongoing Safety Review Orlistat (Marketed as Alli and Xenical); 2009. Available from: http://www.fda.gov/Drugs/DrugSafety/PostmarketDrugSafetyInformationforPatientsandProviders/DrugSafetyInformationforHeathcareProfessionals/ucm179166.htm. Accessed 2010 Sep 9.

107. Greenway FL, Fujioka K, Plodkowski RA, et al. Effect of naltrexone plus bupropion on weight loss in overweight and obese adults (COR-I): a multicentre, randomised, double-blind, placebo-controlled, phase 3 trial. Lancet. 2010;376(9741):595-605.

108. Vetter ML, Faulconbridge LF, Webb VL, Wadden TA. Behavioral and pharmacologic therapies for obesity. Nat Rev Endocrinol. 2010 Aug 3. Epub ahead of print.

109. Klem ML, Wing RR, McGuire MT, Seagle HM, Hill JO. A descriptive study of individuals successful at long-term maintenance of substantial weight loss. Am J Clin Nutr. 1997;66(2):239-246.
110. McGuire MT, Wing RR, Klem ML, Hill JO. Behavioral strategies of individuals who have maintained long-term weight losses. Obes Res. 1999;7(4):334-341.

111. Wyatt HR, Grunwald GK, Mosca CL, Klem ML, Wing RR, Hill JO. Long-term weight loss and breakfast in subjects in the National Weight Control Registry. Obes Res. 2002;10(2):78-82.

112. Cooper Z, Fairburn CG. A new cognitive behavioural approach to the treatment of obesity. Behav Res Ther. 2001;39(5):499-511.

113. Melchionda N, Marchesini G, Apolone G, et al. The QUOVADIS study: features of obese Italian patients seeking treatment at specialist centers. Diabetes Nutr Metab. 2003;16(2):115-124.

114. Dalle Grave R, Calugi S, Corica F, di Domizio S, Marchesini G; QUOVADIS Study Group. Psychological variables associated with weight loss in obese patients seeking treatment at medical centers. J Am Diet Assoc. 2009;109(12):2010-2016.

115. Rhodes RE, Fiala B. Building motivation and sustainability into the prescription and recommendations for physical activity and exercise therapy: the evidence. Physiother Theory Pract. 2009;25(5-6):424-441.

116. Beck J. The Beck Diet Solution: Train Your Brain to Think Like a Thin Person. Birmingham, AL: Oxmoor House Pub; 2007.

117. Stahre L, Hallstrom T. A short-term cognitive group treatment program gives substantial weight reduction up to 18 months from the end of treatment. A randomized controlled trial. Eat Weight Disord. 2005; 10(1):51-58.

118. Stahre L, Tarnell B, Hakanson CE, Hallstrom T. A randomized controlled trial of two weight-reducing short-term group treatment programs for obesity with an 18-month follow-up. Int J Behav Med. 2007;14(1):48-55.

119. Werrij MQ, Jansen A, Mulkens S, Elgersma HJ, Ament AJ, Hospers HJ. Adding cognitive therapy to dietetic treatment is associated with less relapse in obesity. J Psychosom Res. 2009;67(4):315-324.

120. Werrij MQ, Mulkens S, Hospers HJ, Smits-de Bruyn Y, Jansen A. Dietary treatment for obesity reduces BMI and improves eating psychopathology, self-esteem, and mood. Neth J Psychol. 2008;64:8-14.

121. Werrij MQ, Roefs A, Janssen I, et al. Early associations with palatable foods in overweight and obesity are not disinhibition related but restraint related. J Behav Ther Exp Psychiatry. 2009;40(1): 136-146.

122. Cooper Z, Doll HA, Hawker DM, et al. Testing a new cognitive behavioural treatment for obesity: a randomized controlled trial with three-year follow-up. Behav Res Ther. 2010;48(8):706-713.

123. Brownell KD, Horgen KB. Food Fight: the Inside Story of the Food Industry. New York, NY: McGraw-Hill; 2004.

124. Joint WHO/FAO Expert Consultation. Diet, Nutrition and the Prevention of Chronic Diseases. WHO Technical Report No. 916. Geneva, Switzerland: World Health Organization; 2003.

125. Knowler WC, Barrett-Connor E, Fowler SE, et al. Reduction in the incidence of type 2 diabetes with lifestyle intervention or metformin. N Engl J Med. 2002;346(6):393-403.

126. Jeffery RW, Wing RR, Sherwood NE, Tate DF. Physical activity and weight loss: does prescribing higher physical activity goals improve outcome? Am J Clin Nutr. 2003;78(4):684-689.

127. Perri MG, Sears SF Jr, Clark JE. Strategies for improving maintenance of weight loss. Toward a continuous care model of obesity management. Diabetes Care. 1993;16(1):200-209.

Diabetes, Metabolic Syndrome and Obesity: Targets and Therapy

\section{Publish your work in this journal}

Diabetes, Metabolic Syndrome and Obesity: Targets and Therapy is an international, peer-reviewed open-access journal committed to the rapid publication of the latest laboratory and clinical findings in the fields of diabetes, metabolic syndrome and obesity research. Original research, review, case reports, hypothesis formation, expert opinion and commentaries are all considered for publication. The manuscript management system is completely online and includes a very quick and fair peer-review system, which is all easy to use. Visit http://www.dovepress.com/testimonials.php to read real quotes from published authors. 